\title{
EREBEA
}

Revista de Humanidades

y Ciencias Sociales

NúM. 3 (2013), pp. 203-226

ISSN: 0214-0691

\section{LA BIOGRAFÍA COMO GÉNERO HISTORIOGRÁFICO DESDE LA Historia Contemporánea Española*}

\author{
Víctor M. Núñez García** \\ Universidad de Huelva
}

RESUMEN

La biografía es un género historiográfico que forma parte de manera visible de las últimas tendencias de producción e investigación histórica. Su ya no tan novedosa actualidad en el ámbito de la historia científica se analiza en este artículo desde un doble prisma. Por una parte desde el punto de vista del contexto historiográfico en las últimas décadas donde el regreso al individuo y la vuelta a lo político retroalimentan directamente el género biográfico. Por otra parte desde el éxito adquirido por la biografía dentro de la historia contemporánea espańola en los últimos ańos, con especial mención a la biografía colectiva y a derivaciones metodológicas como la prosopografía.

Palabras Clave

Biografía individual, biografía colectiva, Historia Contemporánea española, prosopografía.

Fecha de recepción: 15 de junio de 2013 Fecha de aceptación: 31 de julio de 2013
Abstract

Biography is a genre of historiography that visibly forms a part of recent trends in historical research. Its no longer new place in historical science is examined here from two angles. The first is the historiographic context of recent decades, during which the return to the individual and the turn to the political directly feed the genre. The second angle of study is the success in recent years of biography in contemporary Spanish history, as manifest in collective biography and in methodological derivations such as prosopography.

\section{KEYWORDS}

Individual biography, collective biography, contemporary Spanish history, prosopography

* Este artículo se inscribe en el proyecto de investigación I+D+I "La construcción histórica de la inclusión y la exclusión políticas: España entre Europa y América Latina (1780-1910)” [HAR2012-32637], financiado por el Ministerio de Economía y Competitividad. Este proyecto a su vez está incluido en la red "Historia de las culturas políticas y de las identidades contemporáneas" [HAR2010-12369-E].

*victor.nunez@dhis2.uhu.es 

"Los seres humanos son demasiado importantes para tratarlos como meros sintomas del pasado." (L.Strachey).

"La historia no ocurre fuera de cada experiencia individual y la determina, sino que ocurre dentro, y ahi es donde alcanza valor y sentido." (I. Burdiel).

"Siendo los seres humanos la substancia de la historia, no se podrá conocer algo de la naturaleza y del funcionamiento de un grupo humano sino cuando se sepa algo concerniente a los individuos que lo componen." (J. E. Neale).

\section{INTRODUCCIÓN}

La biografía, biografía histórica o biografía de personaje(s) histórico(s) es un género historiográfico que no ha tenido en España una tradición tan importante como en otros países, en especial en países de habla inglesa ${ }^{1}$, pero que en la actualidad ha adquirido una vigencia apreciable. Por el número de ediciones que alcanza hoy dentro del conjunto de los libros de historia, por la cantidad de lectores que se acercan a ella, y por qué no, por su proyección comercial dentro del mundo editorial, puede afirmarse que la narración con criterios científicos de los diferentes perfiles de los trayectos vitales de personajes del pasado se encuentra actualmente en un período de extraordinario vigor. La ciencia histórica, después de grandes ciclos historiográficos como el positivismo, la historia serial o los estructuralismos y al amparo del giro lingüístico ${ }^{2}$ y de las tendencias post-modernas, ha vuelto a recuperar el género clásico de la biografía adaptado a las actuales bases epistémicas y objetivos de la historia. Contar, narrar, describir vuelven a ser par-

El contenido y las reflexiones de este artículo supone una actualización de lo ya publicado en V. M. Núñez García, "Las elites y la construcción del estado liberal en España (1850-1874)”, en R. Zurita y R. Camurri (eds.), Las elites en Italia y en España (1850-1922), Valencia, Universidad de Valencia, 2008, pp. 61-96.

1 E. Hernández Sandoica, Tendencias historiográficas actuales. Escribir historia hoy, Madrid, Akal, 2004, p. 401.

2 El debate respecto a la narrativización de la historia, íntimamente ligado al giro lingüístico, comenzó en las páginas de la revista Past and Present a través de reputados miembros de la historiografía británica de la segunda mitad del s. XX como L. Stone o E. J. Hobsbawm. L. Stone, "The revival of narrative: reflections on a new old history", Past and Present, vol. 85, no 1 (1979), pp. 3-24; E. J. Hobsbawm, "The revival of narrative: some comments", Past and Present, vol. 86, $\mathrm{n}^{\circ} 1$ (1980), pp. 3-8. 
tes intrínsecas del oficio de historiador/a, haciendo de la biografía individual y colectiva vías de aproximación plausibles a la explicación de épocas pasadas y a la reconstrucción de tramas sociales.

Las dudas sobre el valor cognitivo de la narración biográfica se han ido disipando progresivamente en las últimas décadas, aunque también se debe argumentar la propia capacidad de la biografía para atraer la atención de públicos diversos y, por qué no, sus "bondades" en el ámbito comercial. Dentro de esta revalorización de los aspectos cognitivos de los relatos biográficos, se añaden las enormes potencialidades desde el punto de vista de la Didáctica de las Ciencias Sociales que los ejercicios biográficos pueden aportar a los procesos de enseñanza y aprendizaje, sobre todo teniendo en cuenta las nuevas exigencias del Espacio Europeo de Educación Superior (EEES) para un renovado ejercicio docente universitario en los grados de historia ${ }^{3}$. En efecto, aparte del ejercicio puramente investigador, desde estrategias diversas e innovadoras el ejercicio biográfico también se ha revalorizado visiblemente en los últimos tiempos dentro del ámbito de la Didáctica de las Ciencias Sociales, en este sentido afrontar el proceso de enseńanza y aprendizaje de la historia partiendo de actividades prácticas e indagatorias relacionadas con la biografía se ha convertido en un itinerario docente muy válido para el trabajo de competencias, tan necesario en el marco de la implantación de los grados universitarios, y fundamentalmente en un excelente eslabón de enganche para introducir a todo tipo de alumnado, incluidos Primaria, ESO y Bachillerato, en un determinado período histórico desde el ejemplo significativo de la materia humana.

Por otra parte, los acercamientos biográficos a personajes políticos relevantes de la historia más reciente ${ }^{4}$ y no tan reciente se han potenciado de manera exponencial dentro de los objetivos de los historiadores/as profesionales en los últimos años, tanto en su vertiente individual como en la colectiva. La biografía política, como uno de los objetivos de análisis fundamental en el presente artículo, ha reverdecido y sofisticado sus recursos a medida que se ha ido asentando en la historiografía la llamada vuelta a la política o la nueva historia política 5 .

Esta renovación de los aspectos políticos como objeto historiográfico también se basa en la tendencia a recuperar el relato y narración de la historia como uno de sus puntos nodales, lo que indudablemente se relaciona con géneros expansivos como la biografía histórica en sus diversas vertientes. Las tendencias historio-

3 Sobre estas cuestiones F. Gómez Ochoa, "La Historia Contemporánea, de la Licenciatura al Grado", Ayer, no 85 (2012), pp. 245-256.

4 Personajes como Hitler, Lenin, Stalin o Franco en el caso español han generado una ingente cantidad de biografías, no siempre de procedencia historiográfica, en este sentido desde el ámbito periodístico y desde el ámbito de los historiadores amateurs el género biográfico ha sido uno de los más cultivados.

5 E. Hernández Sandoica, Tendencias historiográficas actuales..., p. 401. 
gráficas recientes, inmersas en el postmodernismo, proponen un acercamiento diverso, ecléctico y transdisciplinar a las realidades históricas, donde los distintos campos de conocimiento logran interaccionar e integrarse a la hora de alcanzar explicaciones del pasado más complejas y completas. En ese sentido el diálogo y los préstamos conceptuales y metodológicos con ciencias sociales como la politología resultan esenciales o, por otra parte, la estrecha relación entre la nueva historia política y la historia social y cultural también está muy presente en las investigaciones más recientes. Un ejemplo muy pertinente de ello podrían ser los usos prosopográficos de la nueva historia política a la hora de reconstruir la historia social del poder e, incluso, su evolución explicativa más reciente hacia un análisis cultural de dicho poder y de los sujetos del mismo ${ }^{6} \mathrm{o}$, en sentido más amplio, la destacada atención que en los últimos años se ha prestado por parte de los historiadores/as profesionales hacia el análisis de la evolución del concepto de cultura(s) política $(s)^{7}$. En este sentido la biografía política, especialmente en sus vertientes colectivas supone un instrumento epistémico y metodológico de indudables potencialidades explicativas que van más allá de la propia historia política. En definitiva, la actualidad historiográfica de la nueva historia política ha logrado retroalimentar positivamente en los últimos años géneros como la biografía histórica y la prosopografía, aplicación metodológica también en fase expansiva dentro de la ciencia histórica.

\section{LA VUELTA AL SUJETO HistóRICO A TRAVÉS DE LA BIOGRAFíA.}

El consabido regreso - dentro de la actual moda de los "regresos" - de la biografía como género en alza es una realidad palpable directamente relacionada con la revalorización y recuperación del papel protagonista del individuo como sujeto/ actor histórico dentro de la historiografía, tratando de superar la deshumanización de las frías estadísticas del cuantitativismo y sus límites, los determinismos económicos del materialismo histórico, los geográficos del estructuralismo braudeliano

6 Recientes aportaciones de Pedro Carasa Soto se encaminan en esa dirección, lo plantea de forma sintética en P. Carasa, "Una mirada cultural a las elites políticas de los primeros pasos del Estado constitucional", Trocadero, no 19 (2007), pp. 31-53; P. Carasa, "La historia de las elites políticas en el parlamento español: de la prosopografía a la historia cultural”, en R. Zurita y R. Camurri (eds.), Las elites en Italia y en España (1850-1922). Valencia: Universidad de Valencia, 2008, pp. 113-134.

7 Un reciente trabajo por ejemplo aborda los orígenes y construcción del sistema representativo español y del propio liberalismo español desde bases metodológicas transdisciplinares, aunque haciendo hincapié en elementos relacionados con la formación de la cultura política del liberalismo español a lo largo del diecinueve. M. Sierra; M. A. Peña y R. Zurita, Elegidos y elegibles. La representación parlamentaria en la cultura del liberalismo. Madrid: Marcial Pons, 2010.También resulta fundamental para situarnos en los debates teóricos más recientes sobre los usos y sentido conceptual del abordaje de la cultura(s) política(s) la obra colectiva de reciente publicación M. Pérez Ledesma y M. Sierra (eds.), Culturas politicas: teoría e historia. Zaragoza: Institución Fernando El Católico (CSIC) y Diputación Provincial de Zaragoza, 2010. 
y los demográficos del malthusianismo ${ }^{8}$. Nuevamente destaca la importancia del individuo para los historiadores profesionales, pero en este caso incluyendo una necesaria ubicación en su contexto, analizando al personaje desde dentro con la pretensión de conocerlo en su relación con las personas, grupo social y el mundo que le rodea ${ }^{9}$. En este sentido, la nueva biografía como instrumento y tendencia que ha recuperado rigurosidad y vigor dentro de la historiografía y el retorno del papel protagónico de los actores históricos confluyen, interaccionan y van de la mano. En puridad, la vuelta al sujeto -individual o colectivo- como objeto de estudio ha puesto en boga el regreso de géneros historiográficos como el biográfico, dentro de la nueva legitimidad alcanzada por lo narrativo, sometido a directrices netamente diferentes a las que lo guiaron tradicionalmente como ya se ha apuntado. Todo ello bajo la adaptación a nuevos planteamientos y necesidades de la investigación histórica actual, superando anacrónicos esquemas de naturaleza descriptiva, positivista e incluso hagiográfica asociados a determinados intereses.

Los historiadores/as dejaron de lado a la biografía en sus objetivos investigadores en las décadas centrales del s. XX, época donde la historiografía estructuralista desacreditó y receló del papel de lo individual y del individuo en la explicación histórica, viéndose relegada la biografía a la condición de género científicamente y "moralmente" sospechoso ${ }^{10}$, fruto de, entre otros complejos procesos, los vaivenes intelectuales que han provocado las tensiones entre la sociedad y el individuo, entre el presumible conocimiento profundo y necesario procedente de lo colectivo y el conocimiento artificial y azaroso procedente de lo individual. Como apunta Isabel Burdiel en su reflexión sobre la biografía histórica, "resulta una simplificación inadmisible el trazado de una línea de sucesión y superación entre un tipo de historia centrada en los individuos con abstracción de toda determinación social -la supuesta historia tradicional decimonónica- y una historia centrada en las estructuras con abstracción de toda trayectoria individual -la supuesta historia científica y estructuralista del siglo XX-. La evolución del pensamiento histórico al respecto ha sido siempre más tortuosa, más contradictoria y vacilante"11.

$8 \mathrm{~J}$. Aurell, La escritura de la memoria. De los positivistas a los postmodernos. Valencia: Universidad de Valencia, 2005, p. 163. Para alcanzar una visión panorámica de la historia de la historiografía y de la evolución de los paradigmas historiográficos en general vid E. Hernández Sandoica, Tendencias historiográficas actuales...; J. Aróstegui, La investigación histórica. Teoría y método. Barcelona: Crítica, 2001; G. Iggers, La ciencia histórica en el siglo XX. Las tendencias actuales. Barcelona: Idea Universitaria, 1998.

9 M. Urquijo Goitia, "Los parlamentarios de Cantabria en el contexto de los diccionarios biográficos de parlamentarios", Ayer, no 67 (2007), pp. 271-272.

10 I. Burdiel, "La dama de blanco. Notas sobre la biografía histórica", en I. Burdiel y M. Pérez Ledesma (coords.), Liberales, agitadores y conspiradores. Biografias heterodoxas del siglo XIX. Madrid: Espasa Calpe, 2000, p. 21.

11 Burdiel, La dama de blanco..., p. 22. 
Ciertamente dentro de la mencionada moda de los "regresos", las apariciones y desapariciones del interés por el bios de las personas en un amplio sentido, los créditos y descréditos por parte de los paradigmas historiográficos, no han hecho más que suscitar nuevas incertidumbres sobre la biografía histórica. Este descrédito historiográfico, originado por el dilema -quizá irresoluble- entre individualismo y estructuralismo metodológicos, provocó que durante años sólo se acudiera al género biográfico desde la literatura, desde la novela concretamente ya que el tratamiento del bios encontró acomodo en la ficción. Aquello que la historia abandonó, creó el espacio para la novela, alejando la práctica de la biografía de la gran corriente de la historia científica y académica ${ }^{12}$.

En todo caso, en los últimos años la reacción de los historiadores/as profesionales, conscientes e inmersos en una nueva fase historiográfica, o la del lector/ consumidor de literatura histórica ante el antihumanismo militante de los paradigmas estructuralistas -tanto en historia, como en sociología o antropología- del $\mathrm{XX}$, ha revitalizado al género biográfico y al individuo/sujeto histórico redescubriendo potencialidades explicativas y metodológicas. Las reflexiones teóricas que justifican esta situación se están haciendo explícitas ${ }^{13}$, usualmente como respuesta a las constantes sospechas respecto a su rigurosidad científica y las nociones estereotipadas denunciadas por sus detractores como leyes inevitables de la biografía, en su mayor parte procedentes de esquemas positivistas decimonónicos. Por tanto, la biografía, rescatada de su proscripción, no sólo ha recuperado su consideración científica y su respeto académico, sino que, incluso, se plantea en algunos foros como una vía alternativa y expedita para resolver y conciliar viejas diatribas analíticas propias del oficio de historiador/a: en especial, la tensión entre el individuo y la sociedad, entre lo particular y lo general, entre lo local y lo universal; en definitiva, entre lo privado y lo público.

Como reflexión muy genérica se parte de la idea de que el historiador/a nunca puede llegar a deslindarse por completo de la mirada al sujeto ${ }^{14}$. Elena Hernández aborda de manera sintética las teorías de la identidad, de la acción y de la interpretación puntualizando que "el interés teórico por la experiencia y la expansión de las teorías de la acción tienen que ver por tanto, indudablemente, con el rever-

12 Burdiel, La dama de blanco..., p. 24.

13 Como uno de los recientes frutos de estas reflexiones vid el número monográfico sobre la biografía histórica de Cercles, no 10 (2007). También cabe destacar por la riqueza de sus contribuciones la obra colectiva J. C. Davis e I. Burdiel (eds.), El otro, el mismo. Biografia y autobiografía en Europa (siglos XVII-XX). Valencia: Universidad de Valencia, 2005.

14 A pesar de que la biografía pueda seguir definiéndose como un género a caballo entre el rigor científico, la aridez de la verificación documental y el relato literario. R. Serrano García (coord.), Figuras de la Gloriosa. Aproximación biográfica al Sexenio Democrático. Valladolid: Servicio de Publicaciones de la Universidad de Valladolid, 2006, p. 9. [En presentación]. 
decer del interés biográfico" ${ }^{15}$. En las ideas, las líneas discursivas, los textos, las fuentes; detrás de todo ello hay individuos, dentro de un contexto, unas circunstancias y una intencionalidad determinada ${ }^{16}$. Por más esfuerzos que se hagan, el historiador/a no puede sortear la biografía a menos que considere posible leer un documento e interpretarlo sin referencia a una intención y, por lo tanto, a un sujeto que actúa y a un contexto en acción ${ }^{17}$, es decir, nociones como experiencia, identidad e intención resultan de una apreciable potencialidad explicativa. Es más, toda producción histórica contiene componentes autobiográficos con diferentes grados de sutileza, el historiador/a como sujeto que reconstruye, ordena, analiza e interpreta el pasado nunca llega a deslindarse en sus producciones de sus propias experiencias formativas, culturales, sociales o, por qué no, políticas. La interrelación entre el/la científico/a y su objeto de estudio supone uno de los pilares fundamentales de las actuales corrientes intelectuales y culturales basadas en la preeminencia del relativismo cognitivo. A ello se le añade la nada desdeñable práctica autobiográfica consciente cultivada por parte de los propios historiadores/as en los últimos tiempos ${ }^{18}$.

Otro elemento susceptible de análisis se ubica necesariamente en el riesgo que corre el "historiador/a-biógrafo/a" de analizar trayectorias individuales partiendo desde sus propios esquemas prefijados de racionalidad, donde se crea la ilusión de sujetos unitarios, coherentes y encaminados hacia un propósito biográfico claro y preciso, lo que cercena indudablemente la visión sobre el individuo al omitir discontinuidades, conflictos, contradicciones, silencios... Y es que uno de los problemas metodológicos fundamentales radica en la complejidad de la labor demiúrgica que afronta el historiador/a en el ejercicio biográfico a la hora de buscar, seleccionar y ordenar las piezas para construir coherentemente un puzle que en la mayoría de las ocasiones necesariamente se presenta como un conjunto

15 E. Hernández Sandoica, Tendencias historiográficas actuales..., p. 405.

16 A modo de ejemplo Rafael Zurita, María Antonia Peńa y María Sierra en uno de sus trabajos, sobre los artífices de la legislación electoral de mediados del XIX y el debate político e intelectual suscitado entorno a los mecanismos de representación política en la construcción del Estado liberal, demuestran que más allá de la adscripción política o las posturas doctrinales, los sujetos se comportaron en el legislativo dirigidos por las circunstancias biográficas individuales. Esto arroja un nuevo enfoque explicativo sobre el, en ocasiones, irregular e ilógico comportamiento de la clase política en esta época, aparte del proveniente del análisis de las líneas ideológicas, discursivas y de cultura política. R. Zurita, M. A. Peńa y M. Sierra: "Los artífices de la legislación electoral: una aproximación a la teoría del gobierno representativo en Espańa (1845-1870)", Hispania, vol. 66, no 223 (2006), pp. 633-670.

17 Burdiel, La dama de blanco..., p. 26.

18 Sobre autobiografía y egohistoria protagonizada por historiadores/as I. Peiró: "La contemplación de Narciso. La <<vocación autobiográfica >> de los historiadores”, en C. Frías y M. A. Ruiz (coords.), Nuevas tendencias historiográficas e historia local en España. Actas del II Congreso de Historia Local de Aragón. Zaragoza: Prensas Universitarias, 2001, p. 364. 
deslavazado de elementos. Sin lugar a dudas el escudrińamiento de los aspectos más sutiles de la imagen y proyección pública de un personaje, aparte de sus perfiles más íntimos y privados, requiere de la aceptación de un cierto margen de desorden y desconexión por la propia naturaleza de una vida humana, donde, parafraseando a Alain Robbe-Grillet, la vida está marcada por la discontinuidad, el azar, la fatalidad o el imprevisto. Aunque los historiadores/as aún nos afanamos por construir un discurso coherente y bien trabado, explicativo y analítico, que, particularmente en el caso de la biografía, encierre entre el nacimiento y la muerte una especie de guión vital en el que, lógicamente a posteriori, todo se vea encadenado y sostenido por un largo cordón de causas y consecuencias. Posiblemente buscar relatos biográficos necesariamente lineales y coherentes en una materia tan maleable y valiosa en sí misma como la vida sea una de las debilidades más recurrentes en los ejercicios biográficos individuales.

Por otra parte, el carácter singular, irreductible y trasgresor de la experiencia individual es el elemento que profundiza las diferencias frente a la supuesta sistematización y homogeneidad de las estructuras consolidadas, pero precisamente enfocar nuestra visión en lo particular y heterogéneo buscando orden, unidad y propósito significativo es lo que otorga valor al sujeto como vía complementaria y alternativa de conocimiento histórico ${ }^{19}$. En este sentido, la biografía individual apunta hacia la recuperación del potencial dinámico y transgresor del individualismo frente a la autoridad paralizante de las convenciones sociales colectivas ${ }^{20}$, el planteamiento de la biografía colectiva o biografía prosopográfica en cambio tiende metodológicamente a considerar al sujeto como parte de colectividades más amplias (sociales, políticas, culturales, nacionales, de género...). A estas ambivalencias añadimos que el género biográfico es susceptible de una compleja categorización que se ha visto enriquecida por la aplicación de determinados enfoques y metodologías: microhistoria -incluso microantropologia-, historias de vida, psicobiografía, autobiografia, historia de género, historia desde abajo, y, además, la historia oral en el caso de personajes recientes.

En todo caso el "historiador/a-biógrafo/a" está constantemente expuesto a una serie de limitaciones de orden metodológico. Como el peligroso "Síndrome de Estocolmo" que puede llegar a atenazarlo, por la necesidad de seguir persiguiendo una presunta realidad que no siempre es fácil de encontrar y que, por lo general, se construye también con vacíos y códigos sólo descifrables en el contexto discursivo y cultural que los genera. Una segunda limitación hace referencia al propio

19 Lytton Strachey, cuya obra ya clásica Victorianos eminentes tuvo un impacto y un éxito comercial extraordinario en la Inglaterra de 1918, apuntó en el prefacio de su libro de biografías que "los seres humanos son demasiado importantes para tratarlos como meros síntomas del pasado". L., Strachey, Victorianos eminentes. Madrid: Aguilar Maior, 1989, p. 24. [Traducción y prólogo de Dámaso López García].

20 Burdiel, La dama de blanco..., p. 26. 
condicionamiento selectivo que las fuentes de información marcan apriori, por lo general las fuentes disponibles privilegian a los individuos socialmente notables y olvidan a la gente común que sólo circunstancialmente deja su huella en los documentos públicos. El sesgo interpretativo resultante de este problema es evidente, y a él se añade otra cuestión de naturaleza heurística: las fuentes nos aproximan normalmente a lo excepcional y nos silencian esas "pequeńas circunstancias", esos aspectos intrascendentes y rutinarios de la vida que, sin duda, constituyen también la materia de lo humano y dotan de continuidad a los procesos sociales. El mencionado sesgo de las fuentes de información ha privilegiado sin lugar a dudas la biografía de personajes "eminentes" procedentes de los estratos más altos de la sociedad, salvo excepciones cada vez menos ocasionales las clases medias y bajas, los campesinos, los obreros, los molineros -Menocchios ${ }^{21}$ - o las mujeres sin una presencia destacada en su contexto social se han constituido como grupos marginados de los ejercicios biográficos.

Una tercera limitación concierne a cómo desde la biografía el historiador/a afronta el problema de definir los límites entre la acción individual y su contexto social. Deslindar el bios de los factores contextuales e influyentes del entorno, sin dejar de apuntar sus interacciones, supone en sí mismo un reto complejo, pero también un horizonte y un desafío metodológico que la biografía nos acerca. Biografía entendida en sentido amplio, no sólo en referencia al ejercicio biográfico individual, ya que la biografía colectiva en este caso logra desentrañar ciertas barreras interpretativas que se ciernen entre el individuo y el contexto social, alcanzando vías de interacción desde el punto de vista metodológico. Otro de estos inconvenientes de orden metodológico alude a la dificultad que el historiador/a encuentra al intentar penetrar en los aspectos psicológicos e identitarios del personaje a biografiar, tratando de descubrir un yo oculto, íntimo, privado e inmanente, distinto e incluso divergente, en cualquier caso, del yo que se manifiesta a través de las expresiones públicas y notorias de su personalidad ${ }^{22}$. Por último mencionar el riesgo que puede llegar a cernirse incluso inconscientemente sobre el historiador/a biógrafo/a de otorgar valores de ejemplaridad y de enseñanza moral al relato biográfico, regresando a los valores más tradicionales en los que se gestó la biografía.

Por otra parte durante las últimas décadas en España, en especial desde finales de los ańos 80 , este mencionado regreso y las reflexiones que han apuntalado la manera en que debe entenderse la investigación biográfica han favorecido el

21 Sin lugar a dudas la obra de Carlo Gizburg y su personaje Menocchio supuso un hito renovador desde el punto de vista historiográfico. C. Ginzburg, El queso y los gusanos. El cosmos según un molinero del siglo XVI. Barcelona: Península, 2009. [Primera edición en Turín, 1976].

22 Cuestión abordada en J. C. Davis, "Decadencia final de una necesidad cultural: la biografía y su credibilidad intelectual", en J. C. Davis e I. Burdiel (eds.): El otro, el mismo. Biografía y autobiografia..., pp. 31-48. 
incremento de nuevas investigaciones consagradas al estudio de sujetos individuales, entre las que encontramos personajes con una mayor o menor significación de su vida en la sociedad, produciéndose una simbiosis entre esta "cultura de la biografía” con unas nuevas demandas lectoras, donde el acercamiento a ciertos personajes potencialmente interesantes e incluso polémicos, y su tratamiento historiográfico o desde otro género en expansión como la novela histórica, se ha convertido en un importante negocio editorial. Negocio, intereses comerciales, nuevos campos de la producción editorial y demandas lectoras por una parte, y por otra, la celebración de efemérides. Fechas clave donde se conmemora el centenario, bicentenario, cincuentenario... de la muerte/nacimiento de cierto sujeto histórico relevante, en las que puede llegar a producirse un desmedido, o más bien irreal, interés y producción literaria e histórica, aunque sin llegar a sobresaturar el mercado editorial bajo el referente común de algún hipotético personaje. Es más, estos eventos pueden llegar a ser necesarios para que instituciones tanto de carácter científico y académico como políticas puedan manifestar y concretar una especial atención por ciertas individualidades, que en fechas de efemérides sirven de incentivo y de guía de toda una serie de intereses relacionados con la producción intelectual y el mundo académico ${ }^{23}$.

En este sentido durante los últimos años hemos asistido a la expansión de un mercado ávido de biografías noveladas al que le falta rigor pero le sobran clientes. El indudable filón comercial alrededor de lo biográfico, como sucede también en un género afín como la novela histórica, ha sido muy bien aprovechado por parte del ámbito de la producción literaria, aún actualmente las producciones biográficas elaboradas desde el campo historiográfico no llegan a "conectar" en la mayoría de las ocasiones con un público más allá del estrictamente académico y profesional, a pesar de los esfuerzos hacia la divulgación. Biografía, biografía novelada novela histórica-, arte, literatura e historia, mercado editorial, demandas lectoras, intereses comerciales, historia divulgativa... Términos que conforman un acervo conceptual sobre el que los historiadores/as profesionales debemos llevar a cabo una profunda reflexión: ¿La historia científica debe aplicar un segmento de sus

23 Por su relativa cercanía, aún mantenemos en nuestra memoria las actividades académicas y científicas que se desarrollaron en el año 2004 con motivo del centenario del fallecimiento de Isabel II: exposiciones, jornadas, congresos, ciclos de conferencias... Además de la publicación de varias biografías en el propio 2004 y sus cercanías que han logrado refrescar la materia, rescribir una nueva historia de la "reina castiza" y desentrańar muchos de los mitos y del conocimiento estereotipado que se ha construido sobre el personaje. Especialmente vid I. Burdiel, Isabel II. No se puede reinar inocentemente. Madrid: Espasa, 2004; J. L. Comellas, Isabel II. Una reina y un reinado. Barcelona: Ariel, 2002; J. S. Pérez Garzón (ed.), Isabel II. Los espejos de una reina. Madrid: Marcial Pons Historia, 2004; G. Rueda: Isabel II. Madrid: Alianza, 2001. De publicación más reciente y evidentemente sin vinculación con el centenario I. Burdiel, Isabel II. Una biografía (1834-1904). Madrid: Taurus, 2010. Esta última obra fue premiada con el Premio Nacional de Historia, nuevo síntoma del papel relevante que está adquiriendo el binomio biografía e historia. 
esfuerzos a cultivar un tipo de biografía histórica limítrofe a lo literario o a lo divulgativo? ¿La biografía elaborada desde la historia científica debe diluirse en las demandas del "gran público", del mercado? ¿La biografía histórica, especialmente en su vertiente individual, supone una ocasión propicia de acercamiento al "gran público" por parte de los historiadores/as profesionales? ¿Sucumbir a los "cantos de sirena" del mercado supondría el principio del fin de la actualidad historiográfica y científica de la biografía histórica? Cuestiones todas ellas sobre las que, reiteramos, se debería reflexionar.

LA BIOGRAFÍA COLECTIVA A TRAVÉS DE LOS DICCIONARIOS BIOGRÁFICOS PROSOPOGRÁFICOS. UN FÉRTIL PUNTO DE ENCUENTRO ENTRE EL GÉNERO BIOGRÁFICO Y LA HISTORIOGRAFÍA CONTEMPORÁNEA ${ }^{24}$.

Los usos colectivos de la biografía, especialmente relacionados con categorías epistémicas y metodológicas como prosopografía, historia social del poder o nueva historia política, también han consolidado en las últimas décadas sin lugar dudas su vigorosidad como género, adquiriendo un especial protagonismo la historiografía contemporánea ${ }^{25}$. Concretamente en referencia a la vinculación

24 Una cuestión muy relacionada como la producción de diccionarios biográficos nacionales es abordada por Mikel Urquijo en su aportación al presente monográfico de Erebea: "Renovación metodológica de los diccionarios biográficos nacionales en el siglo XXI".

25 Sobre categorías conceptuales, epistémicas y metodológicas centrales en esta contribución como sujeto/actor histórico, biografía, prosopografía o incluso elites se han puesto negro sobre blanco en los últimos ańos reflexiones sin lugar a dudas innovadoras, de las que seleccionamos dentro del ámbito historiográfico español R. Zurita y R. Camurri (eds.), Las elites en Italia y en España (1850-1922). Valencia: Universidad de Valencia, 2008; I. Burdiel, "La dama de blanco..., pp. 17-47; P. Carasa (dir.), Elites. Prosopografía contemporánea. Valladolid: Universidad de Valladolid, 1994; P. Carasa, "De la Burguesía a las Elites, entre la ambigüedad y la renovación conceptual”, Ayer, no 42 (2001), pp. 213-237; P. Carasa, "De la teoría de las elites a la historia de las elites", en F. Chacón Jiménez y J. Hernández Franco (coords.), Espacios sociales, universos familiares. La familia en la historiografia española. Murcia: Universidad de Murcia, 2007, pp. 67-106; P. Carasa, "La historia de las elites políticas..., pp. 113-134; P. Carasa, "Una mirada cultural a las elites políticas..., pp. 31-53; J. Pro Ruiz, "Las élites de la España liberal: clases y redes en la definición del espacio social (1808-1931)", Historia Social, no 21 (1995), pp. 47-69; J. Pro Ruiz, "La formación de la clase política liberal en España (1833-1868)", Historia Contemporánea, no 23 (2001-II), pp. 445-481; J. Moreno Luzón, "La historiografía sobre las elites de la España liberal", en R. Zurita y R. Camurri (eds.), Las elites en Italia..., pp. 27-42. M. Pérez Ledesma y I. Burdiel (eds.), Liberales eminentes. Madrid, Marcial Pons, 2008. Más recientemente R. Zurita, "Los autores de la legislación electoral: una perspectiva prosopográfica”, en M. Sierra; M. A. Peña y R. Zurita: Elegidos y elegibles..., pp. 227-268; M. A. Peña y M. Sierra, "Revisitando a prosopografía: uma aproximaçâo ao perfil biográfico colectivo dos deputados espahòis", en J. Moreno Luzón y P. Tavares de Almeida, Das Urnas ao Hemiciclo. Eleiçôes e parlamento em Portugal (1878-1926) e Espanha (1875-1923). Lisboa: Assembleia da República, 2012, pp. 71-99. Desde una perspectiva internacional J. C. Davis y I. Burdiel (eds.), El otro, el mismo. Biografía y autobiografia...; J. Moreno Luzón y P. Tavares de Almeida, Das Urnas ao Hemiciclo...; R. Camurri: "Las elites italianas: estado de los estudios y perspectiva de investigación”, en R. Zurita y R. Camurri (eds.), Las elites en Italia..., pp. pp. 11-25. 
entre conceptos como biografía colectiva y sujetos de la alta política de la contemporaneidad española, en los últimos años el desarrollo de proyectos de investigación centrados en la elaboración de diccionarios biográficos sobre elites de poder político -fundamentalmente de ámbito parlamentario y en menor medida ministerial-, ha demostrado el creciente interés por el tema y su actualidad historiográfica, sobre todo teniendo en cuenta los proyectos ejecutados y que en los últimos años han estado en curso. Tanto a través de estos proyectos grupales como por medio de iniciativas investigativas más individualizadas, en el ámbito editorial español se ha generado un corpus de producción bibliográfica especializada en diccionarios masivos de políticos en las últimas fechas. En el año 1991 apareció un diccionario genérico sobre el Trienio Liberal dirigido por Alberto Gil Novales $^{26}$, dicha obra podría considerarse como pionera o, más bien, como la que dio el pistoletazo de salida a la aparición de este tipo de publicaciones. El propio Gil Novales ha publicado recientemente otro diccionario de similares características, en este caso el período de referencia se desarrolla entre 1808 y $1833^{27}$.

En las últimas dos décadas se han elaborado varias obras de ámbito regional con un planteamiento metodológico no siempre coincidente entre ellas, en las que las pretensiones han sido en mayor o menor medida cubrir la representación parlamentaria, sin que necesariamente se incluyan las dos cámaras colegisladoras (Congreso de los Diputados y Senado) en todos los casos, de ciertas regiones españolas. De entre las publicaciones que comienzan a jalonar el panorama

Por otra parte la producción bibliográfica internacional sobre estas cuestiones también se ha mostrado recientemente pródiga K. F. Werner, "L'apport dela prosopographie à l'histoire social des élites", en K. S. B. Keats-Rohan (ed.), Family Trees and the Roots of Politics. Woodbridge, 1997, pp. 1-21; B. Lacroix, "Six observations sur l'intérêt de la démarche prosopographique daus le travail historiographique”, en J. M. Mayeur; J. P. Chaline y A. Corbin (dirs.): Les Parlementaires de la Troisième République. Paris: Publications de la Sorbonne, 2003, pp. 27-42; K. Verboven, M. Carlier y J. Dumolin, "A Short Manual too the Art of Prosopography", en K. S. B. Keats-Rohan (ed.), Prosopography Approaches and Applications. A handbook. Oxford: Oxford University Press, 2007, pp. 35-69; L. Calovette, "De l'exemple à la série: Histoire de la prosopographie", Siécle, no 10 (1999), pp. 3-19; M. Cotta: L'analisis della clase parlamentare: problema e perspective", Rivista Italiana di Scienza Politica, no 3 (1975), pp. 473-514; F. Andreucci et al.: "L parlamentari in Italia dall'Unitá a oggi. Orientamenti storiografici e problema di ricerca", Italia Contemporanea, no 153 (1983), pp. 145-164; H. Best y M. Cotta (eds.), Parlamentary Representatives in Europe 1848-2000. Legislative Recruitment and Carees in eleven European Countries. Oxford: Oxford University Press, 2000; M. Cotta y H. Best, Democratic Representation in Europe. Diversity, Change and Convergence. Oxford: Oxford University Press, 2010; P. Tavares de Almeida; A. Costa Pinto y N. Bermeo (orgs.), Quem governa a Europa do sul?. Lisboa: Instituto de Ciências Sociais da Universidade de Lisboa, 2006; F. Pitou (dir.), Élite et Notables de l'Quest XVI-XX. Entre conservatisme el medernité. Rennes: Presses Universitaires de Rennes, 2003; E. S. Brezis y P. Temin (coords.), Elites, minorities and economic growth. Amsterdam: Elsevier, 1999.

26 A. Gil Novales (dir.), Diccionario biográfico del Trienio Liberal. Madrid: El Museo Universal, 1991.

27 A. Gil Novales, Diccionario biográfico español (1808-1833). Madrid: Fundación Mapfre e Instituto de Cultura, 2010. 
historiográfico español destacamos los trabajos de Joseba Agirreazkuenaga y su equipo de trabajo en el País Vasco ${ }^{28}$, los de Pedro Carasa y su equipo para Castilla y León ${ }^{29}$, los que han cubierto las regiones gallega ${ }^{30}$ y valenciana ${ }^{31}$, donde se incluyen biografías más breves ya que no se inscriben en un período parlamentario concreto sino que abarcan la totalidad de los siglos XIX y XX. Canarias ${ }^{32}$ o Cantabria ${ }^{33}$ han sido objeto de publicaciones más recientes, con diversidad de pretensiones y en cuanto a la profundidad en el análisis biográfico.

Respecto a Andalucía, cabe señalar la reciente publicación del Diccionario Biográfico de Parlamentarios Andaluces (1810-1869) dirigido por Diego Caro Cancela $^{34}$, como fruto del proyecto de investigación I+D "El Régimen liberal

28 J. Agirreazkenaga et al., Diccionario biográfico de los parlamentarios de Vasconia (1808-1876). Vitoria-Gasteiz: Parlamento Vasco, 1993. Además el Parlamento Vasco ha financiado entre los ańos 2002 y 2006 un proyecto de investigación para la elaboración de un Diccionario biográfico que abarcase la representación parlamentaria de Vasconia desde la Restauración hasta la II República, su resultado editorial se articula como continuidad cronológica de aquella primigenia obra de 1993. J. Agirreazkenaga et al., Diccionario biográfico de los parlamentarios del Vasconia, 1876-1939. 3 vols., Vitoria-Gasteiz: Parlamento Vasco, 2007. Actualmente el grupo de investigación "Biografía y Parlamento" del Departamento de Historia Contemporánea de la UPV/EHU está compuesto entre otros por M. Urquijo, J. Agirreazkuenaga, J. Gracia, F. Martínez, E. Alonso y S. Serrano.

29 P. Carasa (dir.), Elites castellanas de la Restauración, vol. 1, Diccionario biográfico de los parlamentarios castellanos y leoneses (1876-1923), vol. 2, Una aproximación al poder politico en Castilla. Salamanca: Junta de Castilla y León, 1997. Esta obra no sólo plantea el diccionario biográfico como un objetivo en sí mismo, sino que lo articula como una base de datos necesaria y rigurosa de cara al análisis prosopográfico por provincias, que es lo que se incluye en el segundo volumen.

30 X. R. Barreiro Fernández (dir.), Parlamentarios de Galicia: Biografías de diputados y senadores (1810-2001). Santiago de Compostela: Parlamento de Galicia y Real Academia Gallega, 2001.

31 J. Paniagua y J. A. Piqueras (dirs.), Diccionario biográfico de políticos valencianos: 1810-2003. Valencia: Edicions Alfons el Magnánim, 2003.

32 M. B. Barrios Curbelo, Diccionario Biográfico de Diputados Canarios. Madrid: Congreso de los Diputados, 2006. Este trabajo abarca los siglos XIX y XX, por lo que las biografías no son muy extensas, aunque incluyen datos biográficos de interés y se presta especial atención a la materia electoral y a la actividad parlamentaria de los personajes. La propia autora reconoce que su trabajo no pretende ser exhaustivo, por lo que las biografías aspiran a ofrecer un recorrido general de cada individuo y servir de base para futuras investigaciones.

33 A. Garrido (dir.): Diccionario biográfico de los parlamentarios de Cantabria (1902-2002). Santander: Parlamento de Cantabria, 2003 y A. Garrido (dir.): Diccionario biográfico de los parlamentarios de Cantabria (1813-1901). Santander: Parlamento de Cantabria, 2006. El equipo de trabajo dirigido por Aurora Garrido ha producido en las últimas fechas dos diccionarios de parlamentarios cántabros cubriendo el siglo XX y el XIX respectivamente. En el volumen que abarca el siglo XX se introduce la novedad metodológica de incluir a los parlamentarios autonómicos, en el del Diecinueve también se elaboran las biografías de los diputados provinciales elegidos entre 1813 y 1901, con lo que se combina la política local/regional y la nacional.

34 D. Caro Cancela (dir.); J. L. Casas Sánchez; F. M. Espino Jiménez; L. Lozano Salado; F. Martínez López; M. Morales Muñoz; V. M. Núñez García y R. Sánchez García, Diccionario biográfico de los parlamentarios de Andalucía. 1810-1869. 2 vols., Sevilla: Centro de Estudios Andaluces, 2010 . 
en Andalucía: elites políticas, poderes locales y formas de sociabilidad (18101869)", que también dio lugar a la publicación de un monográfico sobre las elites y el poder local en Andalucía $a^{35}$, ambas obras suponen un primer acercamiento a las elites de poder de carácter local y nacional en la Andalucía del primer liberalismo. Nuevamente desde el apoyo editorial del Centro de Estudios Andaluces, destaca la importante aportación de un diccionario biográfico a cargo de Leandro Álvarez Rey que abarca la representación parlamentaria de Andalucía en una etapa histórica muy trabajada por la historiografía andaluza como es la II República, pero que adolecía de un estudio sistemático a escala regional de sus elites políticas ${ }^{36}$.

Más recientemente se ha dado un nuevo paso en la reconstrucción de la historia parlamentaria andaluza desde el prisma de sus elites parlamentarias, en este caso la investigación biográfica de María José Ramos Rovi ha abarcado la representación parlamentaria de las provincias andaluzas durante la Restauración ${ }^{37}$, período muy bien cubierto por la historiografía andaluza en cuanto al análisis de las elites políticas, desde una perspectiva funcional respecto a la formación y puesta en práctica de fenómenos sociopolíticos como el clientelismo y el caciquismo, aunque nuevamente se adolecía de una investigación de conjunto desde una perspectiva biográfica y prosopográfica. También de ámbito andaluz, aunque sin un objetivo específicamente biográfico se hace visible la obra Dos siglos de prostación de J. M. Cuenca Toribio ${ }^{38}$.

Trasladando el campo de investigación de la región o comunidad autónoma a la provincia, en Almería Fernando Martínez López ha dirigido un equipo de trabajo que ha culminado un diccionario parlamentario de ámbito provincial ${ }^{39}$, en Córdoba la tesis doctoral de Francisco Miguel Espino también ha dado lugar a una obra de similares características ${ }^{40}$. En cuanto a la provincia de Huelva y con una cesura cronológica más limitada, incluimos en nuestro monográfico sobre la Década Moderada en Huelva un diccionario biográfico que engloba a sus representantes parlamentarios de dicho período, además de otra obra centrada en los diputados

35 D. Caro Cancela (ed.), El primer liberalismo en Andalucía (1808-1868). Política, economía y sociabilidad. Cádiz: Universidad de Cádiz, 2005.

36 L. Álvarez Rey, Los diputados de Andalucía en la II República: 1931-1939. 3 vols., Sevilla: Centro de Estudios Andaluces, 2009.

37 M. J. Ramos Rovi, Diccionario biográfico de parlamentarios andaluces 1876-1923. Sevilla: Universidad de Sevilla, 2013.

38 J. M. Cuenca Toribio, Dos siglos de prostación: politica y politicos en la Andalucía contemporánea (1810-2006). Sevilla: Ed. José Manuel Lara, 2007.

39 F. Martínez López (dir.), Diccionario biográfico de diputados, senadores y procuradores en Cortes de Almería (1810-1977). Málaga: Unicaja, 2009.

40 F. M. Espino Jiménez, Todos los hombres de Isabel II. Diccionario biográfico de los protagonistas de reinado en Córdoba. Córboba: Asociación de Estudios de Ciencias Sociales y Humanidades de Córdoba; Diputación provincial de Córdoba; Delegación de Cultura de Córdoba, 2009. 
naturales de los actuales territorios de la provincia presentes en las pioneras sesiones parlamentarias de las Cortes de Cádiz ${ }^{41}$.

Asimismo también de forma reciente y bajo la dirección de José Luis Ollero se ha publicado un diccionario masivo de la región de La Rioja, en este caso con una evidente pretensión de amplitud en su campo cronológico al alcanzar a la representación parlamentaria riojana hasta el año $2008^{42}$. Por otra parte, en Cataluña Borja de Riquer está dirigiendo un proyecto de investigación con el objetivo de elaborar el Diccionario biográfico de los parlamentarios catalanes del siglo XX.

En los últimos ańos se ha estado desarrollando un pionero intento de aglutinar en un mismo proyecto de investigación la totalidad de diputados y senadores de la historia parlamentaria española. En concreto se ha ejecutado la primera fase del proyecto genérico "Diccionario biográfico de los parlamentarios españoles", que ha cubierto las fases iniciales del parlamentarismo liberal decimonónico (1810-1854). La pretensión genérica del proyecto es confeccionar las biografías de los parlamentarios que concurrieron a las cámaras españolas desde las Cortes de Cádiz hasta la actualidad, recibe el impulso de la Universidad del País Vasco (coordinadora del proyecto), Universidad Autónoma de Barcelona, Universidad Complutense de Madrid, Universidad de Sevilla y Universidad de Valladolid, la financiación corre a cargo de las Cortes Generales y recibe el apoyo del Centro de Estudios Políticos y Constitucionales. En la fase ya ejecutada se ha organizado una red de grupos de trabajo distribuida por la geografía española y latinoamericana ${ }^{43}$-en referencia a su representación en las Cortes de Cádiz fundamentalmente-, a la espera de la continuidad de dicho proyecto en su segunda fase ya han sido publicados sus primeros frutos editoriales, concretamente a través de la edición de un diccionario biográfico masivo de la primera experiencia parlamentaria en el país, las Cortes de Cádiz ${ }^{44}$, y la publicación en formato CD-ROM del diccionario correspondiente a la etapa parlamentaria 1820-1854 $4^{45}$. El desarrollo

41 V. M. Núñez García, Huelva en las Cortes. Elites y poder político durante la Década Moderada (1843-1854). Huelva: Universidad de Huelva, 2007, pp. 113-180; V. M. Núñez García, Los parlamentarios de Huelva en las Cortes de Cádiz. Discursos y debates políticos. Huelva: Universidad de Huelva, 2012.

42 J. L. Ollero Vallés (dir.), Diccionario biográfico de los parlamentarios de La Rioja (1833-2008). Logroño: Instituto de Estudios Riojanos, 2010.

43 Este proyecto sigue la estela de estrategias similares llevadas a cabo en el entorno europeo, como los ya antiguos Dictionnaire des Parlamentaires Français y el History of Parliament francés y británico respectivamente. M. Urquijo Goitia, Los parlamentarios..., pp. 275-277. Sobre los proyectos llevados a cabo y ejecutados a escala internacional se vuelve mencionar la aportación de Mikel Urquijo al presente monográfico de Erebea: "Renovación metodológica de los diccionarios biográficos nacionales en el siglo XXI".

44 M. Urquijo Goitia (dir.), Diccionario Biográfico de los Parlamentarios Españoles. Cortes de Cádiz, 1810-1814. 3 vols., Madrid: Cortes Generales, 2010 [También disponible en formato CDROM].

45 M. Urquijo Goitia (dir.), Diccionario Biográfico de los Parlamentarios Españoles. 1820-1854. 
de este proyecto y sus resultados ya están proporcionando y proporcionarán una base empírica y un universo analítico/estadístico que permitirá afrontar investigaciones de índole propopográfica sobre el conjunto de los parlamentarios españoles ${ }^{46}$.

De manera genérica y con el objetivo de abarcar la totalidad de las etapas de la historia española y de la Península Ibérica a través de todo tipo de personajes históricos destacados, no sólo de espectro político o parlamentario, en los últimos años se ejecutó un macro-proyecto de investigación ya concluido, el proyecto "Diccionario Biográfico Español" dirigido e impulsado por la Real Academia de la Historia. La ejecución del mismo, posiblemente más conocido para el gran público por la polémica suscitada en los medios de comunicación respecto a la biografía de Francisco Franco redactada por el catedrático de historia medieval Luis Suárez ${ }^{47}$, ha dado como resultado la publicación de la obra Diccionario Biográfico Español ${ }^{48}$ en 30 tomos por parte de la institución académica, aparte de la disponibilidad de una base de datos biográficos básicos en su web aunque sin acceso al contenido de las biografías ${ }^{49}$.

Por otra parte, además del aspecto propiamente parlamentario como parte integrante fundamental de las elites de poder político en la España contemporánea, los afanes biográficos también se han centrado en el ámbito ministerial ${ }^{50}$. En

Madrid: Cortes Generales, 2012 [Edición digital, CD-ROM].

46 Cabe destacar la puesta en práctica de un proyecto similar en Portugal, que dio sus frutos en la publicación en la década pasada de un diccionario biográfico masivo de parlamentarios portugueses. M. F. Monica (dir.), Dicionário Biográfico Parlamentar: 1834-1910. 3 vols., Lisboa: Imprensa de Ciéncias Sociais e Asambleia de República, 2004-2006.

47 Esta polémica saltó en su momento a la palestra del debate público nacional. La Asociación de Historia Contemporánea, entre cuyos asociados hay muchos colaboradores y redactores del proyecto, se posicionó a favor de la revisión crítica del contenido de algunas de sus biografías. [Comunicado de la Asociación de Historia Contemporánea, 30-6-2011. http//ahistcon.org] Recientemente la propia institución académica desoyó las recomendaciones de revisión y corrección por parte de la comunidad científica incluyendo tan sólo correcciones menores y de estilo, más que de contenido. El Pais, Madrid, 24-5-2012. Para profundizar sobre esta cuestión J. L. Ledesma, "El Diccionario Biográfico Español, el pasado y los historiadores", Ayer, no 88 (2012), pp. 247-265.

48 Diccionario Biográfico Español. 30 Vols., Madrid: Real Academia de la Historia, 2009.

$49 \mathrm{http} / /$ www.rah.es/cdeb.html

Este link desde la web de la Real Academia de la Historia enlaza con el Centro de Estudios Biográficos impulsado por la propia academia y el Ministerio de Industria, Turismo y Comercio, creado para la ejecución del Diccionario Biográfico Español.

$50 \mathrm{El}$ interés por los titulares de las carteras ministeriales se ha visto plasmado en varias obras, no siempre con una intencionalidad meramente biográfica ni con el mismo grado de exhaustividad y profundidad en sus planteamientos, entre ellas: J. M. Cuenca Toribio y S. Miranda García, El poder y sus hombres. ¿Por quiénes hemos sido gobernados los españoles? (1705-1998). Madrid: Actas, 1998; J. F. Lasso Gaite, El Ministerio de Justicia. Su imagen histórica (1714-1981). Madrid: Imp. Sáez, 1984; A. Rull Sabater, Diccionario sucinto de Ministros de Hacienda (s. XIX y XX). Madrid: Instituto de Estudios Fiscales, 1991; A. Rull Sabater, Ministros de Hacienda y de Economía de 1700 
este sentido se han desarrollado dos proyectos de investigación bajo la dirección de José Ramón Urquijo Goitia denominados: "Diccionario biográfico de los ministros españoles del siglo XIX" y "Diccionario biográfico de ministros españoles del siglo XX". Ambos financiados por la Dirección General de Investigación Científica y Técnica, de la ejecución de estos proyectos se ha editado una monografía ${ }^{51}$. También se publicaron de forma actualizada los resultados de esta investigación, incluidas las biografías, en la web del Instituto de Historia del Consejo Superior de Investigaciones Científicas, aunque este enlace ya es obsoleto ${ }^{52}$.

Recientes proyectos e iniciativas editoriales por otra parte han dado lugar a la aparición de estudios biográficos colectivos, donde la estrategia se centra en lo individual, dejando de lado objetivos de tratamiento masivo, es decir, no se hace referencia explícitamente a diccionarios colectivos ni a biografía propiamente individual sino que se las podría calificar como "obras mixtas". En estos casos concretos dentro de la historiografía española se propone una selección de salida de naturaleza cronológica, usualmente vinculada al Sexenio Democrático, e ideológica en el que el espectro asociado al liberalismo y a la filosofía del progreso en general, al ideario progresista y a la acción política del partido progresista en particular cobra protagonismo, lo que ha dejado su impronta en varias publicaciones con diversidad de enfoques y objetivos ${ }^{53}$. El planteamiento de este tipo de obras donde se analizan en profundidad -dedicando normalmente un capítulo a cada sujeto- un reducido ramillete de personajes de una época histórica y de una línea política determinada, presenta el inconveniente metodológico de establecer los criterios de selección de una serie de políticos destacados o "eminentes", los cuales no siempre pueden ser nítidos, aparte de las dificultades que acarrea otorgar líneas de continuidad en estas obras en cuanto a los personajes ${ }^{54}$. En este caso, cabría

a 2005. Tres siglos de historia. Madrid: Ministerio de Economía y Hacienda, 2005. Sobre el cuerpo diplomático en Gran Bretaña J. P. Alzina, Embajadores de España en Londres. Madrid: Ministerio de Asuntos Exteriores, 2001.

51 J. R. Urquijo Goitia, Gobiernos y ministros españoles (1808-2000). Madrid: CSIC, 2001 [Segunda edición ampliada en 2008]. Este libro no incluye biografías, su utilidad como obra de consulta radica en la presentación y organización de los datos de los ejecutivos españoles.

52 http://www.ih.csic.es/lineas/jrug/diccionario/ministros

53 Entre ellas I. Burdiel y M. Pérez Ledesma (coords.), Liberales, agitadores y conspiradores. Biografias heterodoxas del siglo XIX. Madrid: Espasa Calpe, 2000; M. Pérez Ledesma e I. Burdiel (eds.), Liberales eminentes...; R. Serrano García (coord.): Figuras de la Gloriosa...; J. Moreno Luzón (ed.), Progresistas. Biografias de reformistas españoles (1808-1939), Madrid: Taurus, 2005; A. GarcíaSanz Marcotegui et al., Los liberales navarros durante el Sexenio Democrático. Pamplona: Servicio de Publicaciones de la Universidad Pública de Navarra, 2005.

54 El propio Javier Moreno Luzón en la introducción de Progresistas. Biografías de reformistas... indica que es imposible encontrar "una única línea de continuidad", entre una serie de personajes que tienen en común el ser etiquetados como progresistas en un sentido amplio del término, pero que a la vez presentan acusadas heterogeneidades y, es que, por ejemplo, escasos nexos de unión podemos encontrar entre Práxedes Mateo Sagasta y Victoria Kent, teniendo también en cuenta la 
preguntarse por los criterios dirigidos a la categorización de un político como importante y por el que merece la pena la elaboración de un capítulo de carácter biográfico ${ }^{55}$.

Como último exponte de esta vitalidad de producciones de naturaleza biográfica, aparte de las ya mencionadas obras de Cantabria en las que se incluyen políticos de ámbito local y nacional, las estrategias biográficas también han fijado sus objetivos en las elites de poder local y provincial. La Universidad de Sevilla bajo la dirección de Rafael Sánchez Mantero está desarrollando un proyecto bajo la intención de confeccionar las biografías de los alcaldes de la ciudad en la contemporaneidad, sin embargo las primeras publicaciones de diccionarios masivos de esta naturaleza han hecho referencia a las zonas vizcaín ${ }^{56}$ y navarra ${ }^{57}$ centrando su atención en los diputados forales y particularmente respecto a los alcaldes, ya han sido publicados dos diccionarios biográficos sobre los consistorios de Valladolid y Bilbao $^{58}$. En este sentido, el descenso de la biografía colectiva y la prosopografía a niveles más primarios, en decir, a lo local, puede permitir la percepción con una mayor nitidez del origen del poder, las características más primarias de este y los mecanismos que se ponen en funcionamiento a su alrededor.

A la luz de lo expuesto los objetivos de la biografía colectiva dentro de la historiografía contemporaneísta española se han orientado preferentemente al análisis grupal de las elites políticas de la edad contemporánea, tanto a escala nacional como provincial y local. La historia es una ciencia social indudablemente presentista donde la relación dialéctica pasado-presente se manifiesta en constante renovación. En momentos como los actuales donde la ciudadanía y nuestra sociedad en general sufre una pronunciada crisis de confianza en los sistemas de gobernanza y en la clase política, el estudio de la génesis histórica de la formación del modelo de estado representativo a través de sus actores históricos/agentes políticos, y

diacronía cronológica. J. Moreno Luzón (ed.), Progresistas. Biografias de reformistas..., p. 12.

55 A modo de ejemplo los editores de la obra Liberales eminentes reconocen que a escala selectiva "no están todos los que son, pero sí todos los que están", argumentando que algunas son figuras muy conocidas y otros personajes son menos reconocibles. En todo caso, la línea común es que todos contribuyeron de forma significativa a la historia del liberalismo español, además adquieren protagonismo "porque han encontrado un biógrafo, o una biografía, empeńados en demostrar lo significativo de su recorrido individual para la experiencia colectiva y para el mejor conocimiento de los problemas de su época”. M. Pérez Ledesma e I. Budiel, Liberales eminentes.., pág. 11. [En presentación].

56 J. Agirreazkuenaga et al., Diccionario biográfico de los diputados generales, burócratas y patricios de Bizkaia. Bizkaia: Biizkaiko Nagusiak, 1995.

57 A. García-Sanz Marcotegui, Diccionario biográfico de los Diputados Forales de Navarra (18401931). Pamplona: Departamento de Presidencia e Interior del Gobierno de Navarra, 1996.

58 P. Carasa (dir.): Diccionario biográfico de los alcaldes de Valladolid. Del absolutismo a la democracia: alcaldes y vida municipal en Valladolid (1810-2010). Valladolid: Ayuntamiento de Valladolid, 2010; J. Agirreazkuenaga y M. Urquijo Goitia (dirs.), Bilbao desde sus alcaldes. Diccionario biográfico de los alcaldes de Bilbao. 3 vols., Bilbao: Ayuntamiento de Bilbao, 2008. 
de la gestación y generalización de ciertos comportamientos y vicios asociados a la práctica política se hace muy pertinente para entender y, por qué no, prevenir muchas situaciones actuales.

\section{UsoS METODOLÓGICOS DE LA BIOGRAFÍA COLECTIVA.}

El ANÁLISIS PROSOPOGRÁFICO.

"La prosopografía es la investigación retrospectiva de las características comunes a un grupo de protagonistas históricos, mediante un estudio colectivo de sus vidas" ${ }^{\prime 5}$.

Al igual que la biografía, la irrupción y puesta en boga de la prosopografía como objetivo investigador $\mathrm{y}$, especialmente, como método para reconstruir una historia social del poder en el caso de las elites políticas, se inserta en el resurgir de la nueva historia politica, completamente alejada de esquemas positivistas del pasado y caracterizada por la incorporación de nuevas metodologías y problemas a resolver. En este sentido, se ha recuperado el género biográfico a escala individual y colectiva como se ha relatado, se han abierto nuevos campos de estudio en materias como la sociología electoral, la historia de los poderes locales, la sociabilidad política, culturas e identidades políticas y nacionales... Respecto a los nuevos métodos incorporados destaca la permeabilidad y versatilidad -en parte- mostrada para adoptarlos desde otras ciencias sociales, es más, la renovación metodológica ha venido de la mano de una mayor profundidad en el análisis conceptual con los instrumentos proporcionados por la ciencia política, la antropología social y la sociología, lo qua ha permitido una clara delimitación de contenidos y objetivos investigadores ${ }^{60}$. A ello añadimos que la ya mencionada recuperación del sujeto histórico -en este caso en su vertiente biográfica colectiva- dentro de la evolución del debate historiográfico actual, ha sido uno de los factores fundamentales del interés y puesta en boga del método prosopográfico, especialmente dirigido hacia el análisis de las elites de poder político en los últimos tiempos ${ }^{61}$.

Más allá de la clásica teoría de las elites de finales del s. XIX y comienzos del XX, de los Pareto, Mosca o Mitchels, o de la compleja conceptualización que se ha manejado en las últimas décadas en las investigaciones prosopográficas, cuestiones que sobrepasan sobremanera los objetivos del presente artículo, estas páginas finales se centrarán en dibujar con brevedad los perfiles metodológicos de la

59 L. Stone, "Prosopografía", en L. Stone, El pasado y el presente. México D. F.: Fondo de Cultura Económica, 1986, pág. 61.

60 R. Sánchez, "La revolución liberal en España. Un estado de la cuestión", en D. Caro Cancela (ed.), El primer liberalismo en Andalucía..., p. 24.

61 En todo caso, como señala Lawrence Stone en su ya clásica reflexión sobre la prosopografía, de manera primigenia esta metodología comenzó a manejarse por la historiografía norteamericana, británica y francesa desde los años 50 y 60. L. Stone: "Prosopografía... 
prosopografía como una vía pertinente para la reconstrucción de la historia social del poder político, sin que ello signifique que los estudios prosopográficos deban centrarse exclusivamente en los escalafones más altos de las sociedades históricas ni en los ámbitos de poder político.

Simultáneamente a la biografía colectiva y, por qué no, partiendo de la misma, la estrategia analítica prosopográfica se ha adaptado muy bien al estudio de las elites, especialmente en su vertiente política, al centrarse en grupos reducidos, por lo que las muestras o universos de análisis resultan accesibles, y por la capacidad de estos grupos de generar documentación lo que redunda en la disponibilidad de fuentes. La definición y el alcance de la prosopografía como método y posible objetivo historiográfico en sí mismo conlleva ciertos inconvenientes teóricos y metodológicos ${ }^{62}$. Una definición muy genérica haría referencia a un uso colectivo de la biografía en cuanto a la utilización de datos biográficos con una finalidad prosopográfica o, más bien, a una biografía colectiva/grupal. Como metodología proporciona mejores resultados cuando se cumplen una serie de condicionantes: debe ser aplicada a un grupo claramente definido y no excesivamente numeroso, enmarcado en un período cronológico igualmente definido y limitado, con fuentes accesibles de tipo variado y complementario y desde una perspectiva analítica destinada a resolver un problema o problemas específicos y claramente plantea$\operatorname{dos}^{63}$. Este método trata de abordar a través de una serie de variables de análisis la producción del sujeto histórico en los ámbitos de actuación político, económico y sociocultural en sentido amplio, así como en los definidos por la familia y las redes sociales, ámbitos todos ellos incluidos en los objetivos de la biografía colectiva.

No se trata tanto de buscar rasgos heterogéneos, sino de aquellos que tienen un carácter previsiblemente común o general y que, precisamente por su repetición, son susceptibles de un tratamiento seriado y del recurso a la cuantificación. La herramienta metodológica de la organización de los datos cuantificables en tablas, gráficos, porcentajes... se adapta de forma óptima a las necesidades del historiador/a dedicado al estudio prosopográfico. Son muchas las variables de análisis que se pueden aplicar a una investigación de esta naturaleza, en ocasiones la disponibilidad de fuentes informativas y lo utópico que resulta completar una "biografía base" con los datos fundamentales de cada miembro del universo o muestra, matiza o reduce las posibilidades de manejo de estas variables.

Entre las de uso común en este tipo de investigaciones podemos encontrar, aunque no siempre en un mismo estudio: la edad, lo que indica el encuadramien-

62 Sobre estas cuestiones de índole teórico L. Stone, "Prosopografía...; P. Carasa (ed.), Elites...; P. Carasa, "De la burguesía...; R. Zurita, "Los autores de la legislación electoral...; M. Sierra y M. A. Peña, "Revisitando a prosopografía..

63 L. Stone, "Prosopografía..., p. 90. 
to del sujeto en una generación política determinada, la edad media de acceso a cargos de representación nacional; la procedencia geográfica; la dimensión política de la elite en cuanto a cargos de política local, provincial y nacional, resultados e incidencias electorales, activismo político, líneas discursivas, propuestas legislativas, desarrollo del cursus honorum político-administrativo, adscripción a grupos, a fracciones políticas o a cierto líder, continuidad, estabilidad e incluso monopolio en los cargos de representación públicos; el perfil formativo en referencia al posible acceso a estudios superiores y en caso afirmativo a qué tipo de títulos abundaban y en qué medida había sujetos que podían iniciar una carrera docente en el ámbito universitario; perfiles profesionales en base a unas categorías previamente establecidas que en ocasiones no responden a las realidades del pasado y que pueden resultar encorsetadas; características económicas, patrimoniales y sobre los perfiles inversores y de negocio; perfiles sociales en cuanto a la continuidad o nueva producción de títulos nobiliarios, espacios de dominio social en el entorno inmediato y espacios de relación social con otros componentes de las elites; las formas de relación de estas elites con el mundo cultural y la vinculación de estos grupos con la familia, el apellido y el linaje.

Por otra parte, los criterios de inclusión/exclusión y la fijación de los límites al colectivo resultan cuestiones que deben establecerse con claridad en la metodología prosopográfica, siguiendo principios institucionales y políticos en el caso de las elites de esta naturaleza. Como una hipotética propuesta genérica podrían incluirse los individuos que han ocupado de forma duradera puestos de poder o influencia -tanto locales como nacionales- y que han tenido la capacidad de tomar decisiones sobre cuestiones de importancia colectiva o influir en quienes las tomaron para hacer prevalecer sus criterios y objetivos. Una parte importante de los diccionarios biográficos masivos publicados hace referencia a la representación parlamentaria de cierta provincia o región, con lo que la clarificación del criterio político e institucional se presentaría extraordinariamente efectiva. Los resultados, en función de la selección de salida y del método aplicado, indudablemente tenderán hacia las particularidades y las especificidades.

En el caso de investigaciones de naturaleza local o regional las conclusiones intentarán ofrecer un resumen que sirva de pauta comparativa con otros de diferentes regiones españolas, de esta forma, se pretende avanzar y tener una visión de conjunto de las elites de poder y del sistema político al que se vinculan. En efecto, la perspectiva de estudio local o microhistórico logra adaptarse a las necesidades del método prosopográfico, articulando una visión de las relaciones entre el poder local y el nacional y de las posibles tensiones centro-periferia en las etapas de consolidación de los diferentes modelos de estado contemporáneos, por ejemplo a través de figuras como los candidatos cuneros. Lo idóneo de este enfoque también se apuntala por la importancia del carácter local en la política contemporánea española, como ámbitos privilegiados -pueblos y ciudades no sólo en España sino 
en la Europa decimonónica- en la construcción de ideario e identidades políticas, en la propagación de nuevas formas de sociabilidad política y en la consolidación de los diversos modelos de estado. En definitiva, la prosopografía se caracteriza por su versatilidad ya que logra combinarse con otras estrategias y perspectivas metodológicas, los análisis locales hacen referencias a enfoques microhistóricos, el cotejo y comparación de los resultados obtenidos con otras investigaciones locales, regionales o nacionales nos introducen en la utilidad e idoneidad de la historia comparada. Por tanto, afrontar este tipo de estudios desde una postura interdisciplinar indudablemente redunda en la optimización y amplitud de miras de los resultados e interpretaciones.

Los límites de la prosopografía han sido argumentados al considerarla como una metodología y herramienta de análisis de utilidad más que como una teoría de conocimiento o para alcanzarlo, es decir, está más valorada en su vertiente metodológica que en su posible categorización como género o tendencia historiográfica. Se asume que el método ofrece fructíferas posibilidades a la hora de localizar, establecer y ordenar los datos asociados a las diferentes variables de análisis proporcionando un marco empírico, pero con limitaciones interpretativas, ya que no logra explicar problemas de calado histórico como los procesos de cambio social y político, la naturaleza del poder que detentan las elites analizadas, las relaciones entre diferentes elites, las de estas con la sociedad y la de los individuos con ellas o los orígenes y desarrollo de las actuaciones de los actores. Esta visión un tanto pesimista también se debe al encasillamiento de esta metodología en lo cuantitativo por su manera de presentar los resultados de forma seriada y sus apriorísticas implicaciones descriptivas, o su posible encasillamiento exclusivo en la historia política.

En todo caso, desde una perspectiva más optimista la prosopografía podría considerarse tanto método como objetivo en sí mismo, al pasar de la localización, ordenación y presentación cuantitativa de los datos a las interpretaciones cualitativas de los mismos. Posiblemente haya cuestiones como las citadas de la naturaleza del poder político o el cambio político-social que no puedan ser explicados en su totalidad desde un análisis sociológico de los sujetos de poder, pero la aplicación correcta del método nos lleva hacia una historia social de la política, incluso de las mentalidades, comportamientos y pautas de conducta -si las fuentes lo permiten-como reflejo de ese poder. Todo lo apuntado supone un pilar más para construir una reflexión solvente sobre la naturaleza del poder en última instancia. La utilidad de estos estudios se multiplica si se abordan estas investigaciones desde una perspectiva más amplia y multidisciplinar, cuestiones como la sociología electoral -vía de acceso al poder institucionalizado-, el análisis de la práctica política, las líneas discursivas, la ideología, la cultura política en un sentido amplio, las redes de relaciones interpersonales o las formas de sociabilidad harán posible llegar a interpretaciones de conjunto sobre el poder y las elites vinculadas a este. 
Como tendencia o género historiográfico también puede jugar un papel fundamental dentro de la actual revalorización del individuo para alcanzar el conocimiento histórico, sobre todo porque metodológicamente consigue articular lo individual y lo colectivo ${ }^{64}$; además también logran articularse en los análisis prosopográficos lo local y lo nacional, tanto el poder político como el social y el económico. En puridad, este método supone una herramienta para la historia política y la social, de ahí su utilidad de cara a superar exclusivismos epistémicos del pasado donde se contraponían estas dos vertientes históricas. Por otra parte esta técnica ofrece la posibilidad de introducir elementos narrativos -como biografía colectiva- y da lugar a un cierto relato histórico, con lo que se puede llegar a dar una historia más ágil y atractiva para el lector, por último, permite con mayor naturalidad la integración de diversos géneros históricos y la utilización de diferentes técnicas interdisciplinares como ya se ha apuntado.

64 En el caso concreto de la elite política, ésta cuenta con un fuerte componente individual, pero simultáneamente tiene una naturaleza colectiva, al estar vinculada en sus ámbitos de actuación, sociabilidad e incluso vida privada a familias, grupos de poder, fracciones políticas, clientelas... 